

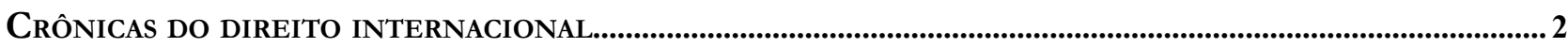

Nitish Monebhurrun

Alice Rocha da Silva

Julia Motte-Baumvol

Rafael Freitas de Oliveira

Roberta Greco

CRÔNICAS DO DIREITO INTERNACIONAL DOS INVESTIMENTOS .11

Nitish Monebhurrun

Reconhecimento E ExecuÇão de Sentenças Estrangeiras: anÁlise do projeto Em andamento na Conferência da Haia de Direito Internacional Privado

Nadia de Araujo

Fabrício Bertini Pasquot Polido

Os CASAMENTOS E AS PARCERIAS ENTRE PESSOAS DO MESMO SEXO NO DIREITO INTERNACIONAL PRIVAdO BRASILEIRO: ASPECTOS TRANSNACIONAIS DAS FAMÍLIAS CONTEMPORÂNEAS.

Bruno Rodrigues de Almeida

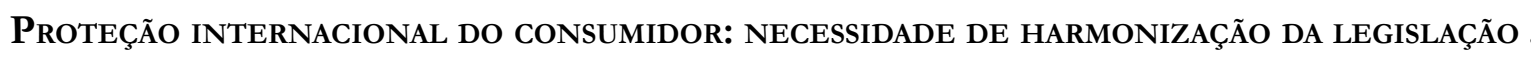
54

Héctor Valverde Santana

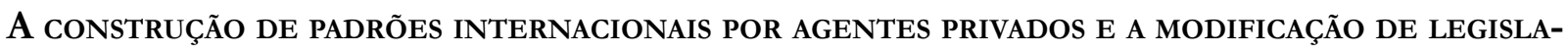
Ção NACIONAL: ALTERAÇÃo do PADRÃo DE CONTABILIDADE PARA EMPRESÁRIOS NO BRASIL.

Cleíse Nascimento Martins Costa

THE DEBATE ON COMPANIES' LIABILITY FOR INTERNATIONAL ENVIRONMENTAL DAMAGES: A COMPARISON BETWEEN THE JURISDiCTIONAL RULES OF THE EUROPEAN UNION AND THE UNITED STATES

Carina Costa de Oliveira

DesenVOlVIMENTO E APLICAÇÃo DA TEORIA dos VíNCUlOS MAIS ESTREITOS NO DIREITO INTERNACIONAL PRIVADO: POR UMA REDISCUSSÃO DO MÉTODO DE SOLUÇÃO DO CONFLITO DE LEIS 101

Jamile Bergamaschine Mata Diz

Rodrigo Vaslin Diniz

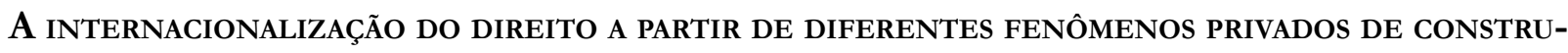
ÇÃO NORMATIVA 117

Fernando Lopes Ferraz Elias 
Leilane Serratine Grubba

Human TRAFFicking: IDENTIFYING FORCED LABOR IN MULTINATIONAL CORPORATIONS \& THE IMPLICATIONS OF LIABILITY

Tara M. Parente

Aplicação dos princípios UNIDROIT no Plano Brasil maior: o SUPRIMENTO de UMA lacuna NA POLÍTICA BRASILEIRA DE DESENVOLVIMENTO ECONÔMICO

Guilherme Freire de Melo Barros

Marcelle Franco Espíndola Barros

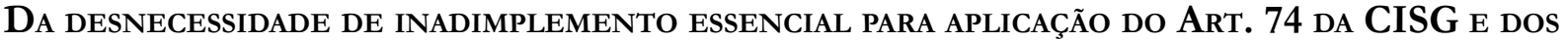
DANOS EFETIVAMENTE RECUPERÁVEIS

Renata Caroline Kroska

ESSAY ON UNEQUAL TREATIES AND MODERNITY THROUGH THE EXAMPLE OF BILATERAL INVESTMENT TREATIES

Nitish Monebhurrun

CONCEITOS DE RELAÇÕES INTERNACIONAIS E TEORIA DO DIREITO DIANTE DOS EFEITOS PLURALISTAS DA GLOBALIZAÇÃO: GOVERNANÇA GLOBAL, REGIMES JURÍDICOS, DIREITO REFLEXIVO, PLURALISMO JURÍDICO,

CORREGULAÇÃO E AUTORREGULAÇÃO . 216

Gabriela Garcia Batista Lima

\section{Outros Temas}

CONVENÇão SOBRE OS DIREITOS DAS PESSOAS COM DEFICIÊNCIA: COMO "INVISÍVEIS" CONQUISTARAM SEU ESPAÇO .230

Luana da Silva Vittorati

Matheus de Carvalho Hernandez 


\title{
A construção de padrões internacionais por agentes privados e a modificação de legislação nacional: alteração do padrão de contabilidade para empresários no Brasil ${ }^{*}$
}

\author{
The construction of international standards \\ for private agents and the change in national \\ legislation: modifying the accounting standard for \\ companies in Brazil
}

Cleíse Nascimento Martins Costa**

\section{Resumo}

O Brasil adotou as Normas Internacionais de Contabilidade, mais comumente conhecido como International Financial Reporting Standards (IFRS) a partir de 2008, com a promulgação da Lei $n{ }^{\circ} 11.638$, de 28 de dezembro de 2007. A principal mudança introduzida pela convergência com as normas internacionais refere-se a mudanças nas práticas contábeis adotadas no Brasil, que passa a ser baseada na interpretação dos pronunciamentos do Comitê de Pronunciamentos Contábeis (CPC) afastando a aplicação das regras nacionais, como no passado recente. Por meio do estudo das regras adotadas pelo CPC vislumbra-se verificar a modificação do padrão instituído a partir da realidade local, as Micro e Pequenas Empresas possuíam um tratamento diferenciado quanto a obrigação de escrituração contábil, e este padrão sofre substancial modificação a partir da adoção dos padrões internacionais de escrituração.

Palavras-chave: Convergência contábil. Normas internacionais de contabilidade. International Financial Reporting Standards. Direito internacional.

\begin{abstract}
Brazil adopted the International Accounting Standards, more commonly known as International Financial Reporting Standards (IFRS) from 2008, with the enactment of Law No. 11,638, of December 28, 2007. The main change introduced by convergence with the standards International refers to changes in accounting practices adopted in Brazil, which happens to be based on the interpretation of the pronouncements of the Accounting pronouncements Committee (CPC) away from the application of national rules, as in the recent past. Through the study of the rules adopted by the CPC, this article is going to verify the changes in the pattern established from the local reality. The conclusion is that Small Business had differential obligation of accounting, and substantial changes from international accounting standards was established by the international standard.
\end{abstract}

\footnotetext{
*Professora do Centro Universitário de Brasília - UniCEUB. Mestra e Doutoranda em Direito. E-mail:

cleisemartins@gmail.com

*Recebido em 10.02.2014

Aceito em 15.05.2014
}

Key-words: Accountant convergence. International accounting standards. International financial reporting standards. International law 


\section{Introdução}

No contexto de complexa interação na formação de normas, nota-se a alteração da tradicional teoria de formação da norma. O Estado possui a prerrogativa da produção de normas no âmbito interno, todavia, é uma modificação dos padrões na produção das normas internas, na medida em que, nota-se que padrões internacionais, não estabelecidos em tratados, ou seja, fora do âmbito do consentimento estatal, passam a ser incorporados ao ordenamento jurídico interno.

Este processo identificado insere-se no contexto de expansão da influencia do direito internacional, e preocupação acerca dos padrões adotados pela majoritária teoria do direito internacional, onde são desconsideradas as ingerências dos atores privados na formação do direito interno.

O que se propõe na presente analise é analisar a modificação do padrão contábil para Micro e Pequenas Empresas no Brasil. Tal situação torna-se relevante para a presente análise visto que, recentemente no Brasil, o padrão de contabilidade para empresário foi modificado em virtude da adoção dos padrões internacionais de contabilidade, produzidos pelo Conselho de Normas Internacionais de Contabilidade (IASB) que é a organização internacional que publica e atualiza as International Financial Reporting Standards (IFRS), que são padrões internacionais de contabilidade.

Conselho de Normas Internacionais de Contabilidade (IASB) é um órgão independente emissor de pronunciamentos contábeis. É supervisionado por uma junta de curadores (IFRS Foundation Trustees) e presta contas ao Conselho de Monitoramento (Monitoring Board) constituído por autoridades representativas do mercado de valores mobiliários, e ex-membros de órgãos governamentais dos Estados.

Tal fato se deu pela atuação do Conselho Federal de Contabilidade (CFC) que adotou os pronunciamentos emitidos nos últimos anos pelo Comitê de Pronunciamentos Contábeis (CPC), os quais tiveram como base as normas internacionais. A princípio, a adoção pelo CFC torna obrigatória a regra para todos os contadores do país. A presente análise não se propões a estabelecer uma análise valorativa do novos padrões, o problema enfrentado refere-se a constatação acerca influencia de atores privados nna esfera internacional e a ingerência dos padrões internacionais, por eles elaborados, no direito empresarial nacional.

\section{Contexto de expansão do direito internacional e os padrões nacionais de contabilidade.}

O moderno direito internacional pretende estabelecer um contraste que revele a solução de questões econômicas, sociais, culturais, técnicas, visando regular questões referentes à desenvolvimento, direitos humanos, comunicação, meio ambiente, educação, trabalho, ciência e tecnologia, alimentação, saúde recursos naturais e energia. Em suma, a expansão do direito internacional gira em torno de elementos que, histórica e essencialmente, sempre estiveram sob a égide da soberania interna do Estado. ${ }^{1}$

Pode ser vislumbrado determinado enfraquecimento da soberania do Estado em determinadas áreas na medida em que há expansão do direito internacional, que passa a regular temas de modo que parte das escolhas nacionais são feitas em escala internacional. ${ }^{2}$ A criação de regimes jurídicos internacionais para regulação de campos da vida social se estende por uma imensa quantidade de assuntos que antes era regida, exclusivamente, pelo direito doméstico. ${ }^{3}$

1 As origens do Direito Internacional remontam à paz de Westfália no século XVII e ao princípio a ela subjacente, de que os Estados europeus formariam um sistema único, fundado no Direito Internacional e no equilíbrio de poder - um direito exercido entre os Estados e não acima deles. O desenvolvimento conceitual e doutrinal desse direito deve-se, principalmente, à expansão do capitalismo mercantil entre os séculos XVIII e XIX, à multiplicação dos Estados independentes, às conseqüências das guerras napoleônicas e à disposição dos países hegemônicos de regular, juridicamente, as relações com outras nações. Assimetria de poder existente à época impedia o Direito Internacional de disciplinar a força utilizada na competição imperialista pelo controle dos recursos naturais e nas disputas militares por áreas geograficamente estratégicas. Assim, após o Congresso de Viena, no século XIX, os esforços para manutenção do equilíbrio sistêmico da época conferiram ao Direito internacional moderno seus principais traços. Dessa forma, em primeiro lugar, o Direito Internacional é marcado pela descentralização de jurisdição, pela heterogeneidade de seus sujeitos e pela complexidade de seu objeto. Em segundo lugar é um direito expresso por meio de acordos, de tratados e de convenções que estabelecem, mantêm e modificam uma complexa cadeia de relações políticas, econômicas, sociais e militares, o que, consequentemente, exige sofisticada ação diplomática para implementar essas regras. Em terceiro lugar, o direito internacional é altamente politizado, tendo em vista que seus princípios e normas são considerados como instrumentos de interesses particulares das nações, que variam de acordo com a dimensão de suas economias, de suas reservas naturais e de suas forças militares. COMBACAU, Jean. Le droit international: bric-àbrac ou système. Archives de philosophie Du droit, Paris, Sirey, n. 31, p. 88, 1986.

2 DUPUY, Pierre-Marie. L'unité de La ordre juridique international: cours general de droit international public. Leiden/Boston: Académie de Droit International de la Haye, 2003. p. 116.

3 Para mais detalhes ver: BADIE, Bertrand; SMOUTS, MarieClaude. La retournement du monde. Fondation National des Sciences 
Paralelamente a esse desenvolvimento normativo em esfera internacional, onde o Estado possui um papel ainda relevante, nota-se que em determinados campos mais técnicos e cujo interesse privado é predominante, o Estado não é mais protagonista na produção de normas. Verifica-se a existência de um conjunto de normas que avança de modo autônomo e paralelo às normas produzidas pelos Estados, e que podem consistir na produção de ordenamentos jurídicos globais. Caracterizados justamente pela sua relativa independência dos ordenamentos nacionais, pela sua capacidade de auto reprodução e de coordenação em escala mundial. A produção normativa em bases não políticas possui uma lógica estritamente mercantilista, esses sistemas concorrem cada vez mais com a política internacional e com os sistemas jurídicos nacionais. ${ }^{4}$

Assim, cabe citar que é assumida a existência de regimes jurídicos com lógica autônoma, os quais, no entanto, buscam a interação entre o internacional e o nacional, e caracterizam a condição fragmentada do direito internacional. Ao se considerar que existe uma condição fragmentada do direito internacional é necessário visualizar a estrutura dessa fragmentação. A fragmentação jurídica é apenas resultado da fragmentação da sociedade global, Todavia, é interessante analisar como os vários regimes jurídicos contidos no direito internacional se expandem a ponto de influenciar a formação de interesses nacionais. ${ }^{5}$

A mundialização induz à internacionalização dos sistemas normativos e de comportamentos judiciários nacionais e à nacionalização do direito e dos procedimentos internacionais. Considera-se que o direito ser internacionalizado significa interação entre ordenamentos, que pode ser definida, por meio de três processos muito estudados do direito

Politique, 1995. p. 45-55.

4 TEUBNER, Gunther. Global Bukowina: Legal Pluralism in the World Society. In: TEUBNER, Gunther (Ed.). Global Law Without a State. Dartmouth: Aldershot. 1997; e, TEUBNER, Gunther. Unitas Mutiplex: corporate governance in group enterprises.

5 TEUBNER, Gunther. Regime-Collisions: The vain search for legal unity in the fragmentation of global law. Michingan Journal of International Law. v. 25, n. 999, Summer 2004. da integração: coordenação $^{6}$, harmonização ${ }^{7}$ e uniformização ${ }^{8} /{ }^{9} / 10$

O principal ponto de discussão é pautado na assertiva de que todo processo de trocas entre normas, jurisprudência e, por vezes, políticas públicas e decisões administrativas, podem está à margem da construção do direito estatal.

A construção do direito no âmbito internacional implica necessariamente na visualização de que os atores privados, como as empresas transnacionais, possuem força normativa, no entanto, estão alheios à

6 A coordenação pode ser entendida a partir da ideia de interação jurídica, seja entre mesmos níveis (internacional-internacional) ou entre níveis diferentes (internacional-nacional). O processo de coordenação é marcado, principalmente, pela interação de jurisprudências (intercruzamento judiciário) e de normas (intercruzamento normativo).36 A interação entre normas e jurisprudência é mais conhecida no direito internacional como o processo de fertilização cruzada que surge como denominação da padronização de conceitos e decisões que emergem como consequência à proliferação de Tribunais e Cortes internacionais no âmbito de um direito internacional descentralizado que não prevê estrutura judicial integrada. DELMASMARTY, Mirelle. Le force imaginantes du droit. le pluralisme ordonné. Editions du Seuil, 2006. p.35.

7 A harmonização é considerada forma de integração que não impõe a conformidade estrita das regras nacionais com os padrões internacionais. É um processo para integrar o nacional e o internacional no qual nota-se uma relação vertical, ou seja, há instauração de uma relação hierárquica entre os níveis mundiais, regionais e o nível nacional. Essa relação hierárquica decorre do objetivo de integração normativa e judiciária que a caracteriza. No entanto, esse processo exclui a composição ou recomposição na forma de um código unificado em escala mundial ou regional preservando certo grau da identidade nacional. DELMAS-MARTY, Mirelle. Le force imaginantes du droit: le pluralisme ordonné. Editions du Seuil, février 2006. p. 35.

8 A unificação repousa sobre o princípio da identidade, no qual as práticas nacionais devem ser idênticas à regra comum. Teoricamente seria a integração perfeita ao ignorar a margem nacional de apreciação, uma vez que ao excluir as diferenças é alcançada a ordem jurídica, regional ou mundial, sob o modelo de hierarquia e de coerência da ordem jurídica nacional. Apesar de ser o reduto da segurança jurídica, a unificação é difícil de ser aceita em áreas mais divergentes. A adoção de uma regra única corre o risco de tornar-se um modo tangencial de impor um sistema hegemônico. DELMAS-MARTY, Mirelle. Le force imaginantes du droit: le pluralisme ordonné. Editions du Seuil, 2006. p. 104. Ver também: ROULAND, N. Anthropologie juridique. PUF, 1998. E ainda SACCO, Rodolfo. L'idée de droit commun par circulation de modèle et par stratification. In: Ruiz-Fabri, Helene; DELMAS-MARTY, Mirelle (Org.). Variations autour d'um droit commun. p.195-199.

9 Não significa que existam somente essas formas de interações jurídicas.

10 BURGORGUE-LARSEN, Laurence. A internacionalização do diálogo dos juizes. Disponível: em: <http://xa.yimg.com/kq/ groups/19791041/384304764/name/Laurence[1].pdf. p.3-4.>. Acesso em: 07 jun. 2010. 
regulação dos Estados e decorrência da pluralidade de jurisdições em que se encontram. A partir destes pontos, visualiza-se um conjunto de princípios, instituições e regras provenientes de diversas fontes, que sustenta as estruturas legais e a atividade específica da coletividade dos operadores do comércio internacional.

Um caso que pode demonstrar o movimento acima descrito é a incorporação dos padrões contábeis para empresários ao ordenamento jurídico brasileiro. O Brasil passou a adotar as Normas Internacionais de Contabilidade, mais comumente conhecidas como International Financial Reporting Standards (IFRS), a partir de 2008, com a promulgação da Lei 11.638, de 28 de dezembro de 2007. A principal mudança instituída pela convergência às normas internacionais refere-se à alteração da prática contábil brasileira, que passa a estar muito mais baseada na interpretação dos pronunciamentos do Comitê de Pronunciamentos Contábeis (CPC) do que na aplicação de regras nacionais, como no passado recente. Tal fato possui implicações acentuadas para a qualidade da informação contábil para o profissional da contabilidade, e principalmente para investidores e analistas do mercado financeiro.

Neste contexto, destaca-se a aprovação de uma resolução do Conselho Federal de Contabilidade do Brasil, a Resolução n ${ }^{\circ}$ 1.418/12, a qual aprova a ITG 1000, que instituiu o modelo contábil para Microempresa e Empresa de Pequeno Porte, questiona-se a adoção de padrões contábeis internacionais. As pequenas e médias empresas têm grande dificuldade em informatizar seus processos e tratá-los de forma integrada. Geralmente, usam tabelas e planilhas eletrônicas, armazenadas em locais diferentes e dissociadas umas das outras. O código civil traz a obrigatoriedade da existência de um sistema de contabilidade por parte, como regra, de todo e qualquer empresário e sociedade empresária.

\section{Art. 1.179. O empresário e a sociedade empresária são obrigados a seguir um sistema de contabilidade, mecanizado ou não, com base na escrituração uniforme de seus livros, em correspondência com a documentação respectiva, e a levantar anualmente o balanço patrimonial e o de resultado econômico. $^{11}$}

Destaca-se que, a escrituração contábil, além de ser uma exigência da legislação comercial e fiscal, é

11 BRASIL. Lei n. 10.406, de 10 de janeiro de 2002. Institui o Código Civil. Disponível em: < http://www.planalto.gov.br/ ccivil_03/leis/2002/110406.htm>. Acesso em: 2 jun. 2014. uma imposição da legislação societária e falimentar. Conforme se pode notar pelos dispositivos legais a seguir: A Lei das Sociedades por Ações (Lei n. $6.404 / 76)^{12}$ define:

Art. 177 - A escrituração da companhia será
mantida com observância aos preceitos da
legislação comercial e desta lei, e aos princípios
de contabilidade geralmente aceitos, devendo
observar métodos ou critérios contábeis uniformes
no tempo e registrar as mutações patrimoniais,
segundo o regime de competência.
§2o A companhia observará exclusivamente
em livros ou registros auxiliares, sem qualquer
modificação da escrituração mercantil e das
demonstrações reguladas nesta Lei, as disposições
da lei tributária, ou de legislação especial sobre a
atividade que constitui seu objeto, que prescrevam,
conduzam ou incentivem a utilização de métodos
ou critérios contábeis diferentes ou determinem
registros, lançamentos ou ajustes ou a elaboração
de outras demonstrações financeiras. (Redação
dada pela Lei no 11.941 , de 2009 )

A Lei de Falências (Lei no 11.101), que regula a recuperação judicial, a extrajudicial e a falência do empresário e da sociedade empresária, estabelece no art. 51, inciso II e no art. $163 \int 6^{\circ}$, inciso II, que a petição inicial de recuperação judicial e extrajudicial será instruída com as demonstrações contábeis relativas aos três últimos exercícios sociais e as levantadas especialmente para instruir o pedido, confeccionadas com estrita observância da legislação societária. ${ }^{13}$

Art. 51 A petição inicial de recuperação judicial
será instruída com:
II - as demonstrações contábeis relativas
aos 3 (três) últimos exercícios sociais e as
levantadas especialmente para instruir o pedido,
confeccionadas com estrita observância da
legislação societária aplicável e compostas
obrigatoriamente de:

a) balanço patrimonial;

12 BRASIL. Lei n. 6.404, de15 de dezembro de 1976. Dispõe sobre as Sociedades por Ações. Disponível em: <http://www.planalto. gov.br/ccivil_03/leis/16404consol.htm>. Acesso em: 2 jun. 2014.

13 BRASIL. Lei n. 11.101, de 9 de fevereiro de 2005. Regula a recuperação judicial, a extrajudicial e a falência do empresário e da sociedade empresária. Disponível em: <http://www.planalto.gov. br/ccivil_03/_ato2004-2006/2005/lei/111101.htm>. Acesso em: 2 jun. 2014. 
b) demonstração de resultados acumulados;

c) demonstração do resultado desde o último exercício social;

d) relatório gerencial de fluxo de caixa e de sua projeção;

e

Art. 163 \6o Para a homologação do plano de que trata este artigo, além dos documentos previstos no caput do art. 162 desta Lei, o devedor deverá juntar:

II - as demonstrações contábeis relativas ao último exercício social e as levantadas especialmente para instruir o pedido, na forma do inciso II do caput do art. 51 desta Lei;

Além dos fundamentos legais citados, a escrituração contábil pode servir de base para: distribuir lucros, compensar prejuízos, elaborar as demonstrações financeiras (contábeis), provar, em juízo, sua situação patrimonial, em questões que possam existir com herdeiros e sucessores do sócio falecido, requerer concordata, por insolvência financeira, provar a sócios que se retiram da sociedade a verdadeira situação patrimonial da empresa, para fins de restituição de capital ou venda de participação societária, entre outros.

Em um contexto de tratamento favorável às MPEs, a Lei Complementar no123, de 14 de dezembro de 2006, dispôs que as Microempresas e Empresas de Pequeno Porte devem seguir um procedimento de escrituração contábil simplificado. Assim, em dezembro de 2007, o Conselho Federal de Contabilidade editou a Norma Brasileira de Contabilidade - NBC T 19.13, a qual estabeleceu os procedimentos da Escrituração Contábil Simplificada.

No entanto, em 2009 a NBC T 19.13 foi revogada, pois houve uma modificação das normas sobre escrituração contábil por meio da Lei n. 11.638/11, e as MPEs passaram a ser normatizadas pela NBC TG 1000 - Contabilidade para Pequenas e Médias Empresas, aprovada pela Resolução CFC no 1.255, editada no mesmo ano, e que impunha obrigações sem diferenciação em razão do porte das empresas.

Com a necessidade de estabelecer tratamento contábil diferenciado para as MPEs, foi aprovada a ITG 1000. A ITG 1000 visa desobrigar esse conjunto de empresas da adoção da Norma Brasileira de Contabilidade Técnica Geral - NBC TG 1000 - Contabilidade para
PMEs (equivale a norma internacional para PME), consentindo-lhes adotar um modelo mais simplificado para a escrituração e elaboração de demonstrações contábeis.

Cumpre ressaltar que, para o fisco, a escrituração é meio destinado a alcançar resultado de interesse da tributação (arrecadação), enquanto, para a Contabilidade, a escrituração tem por finalidade registrar, preservar e garantir a verdade econômicofinanceira da entidade. A escrituração é, portanto, obrigatória, em qualquer empresa, e o é por força de lei. A dispensa da escrituração contábil completa refere-se apenas à legislação do Imposto de Renda, não estando a empresa desobrigada da escrituração exigi da pela legislação comercial, societária e falimentar. ${ }^{14}$

No caso de ME e EPP optantes pelo Simples Nacional os registros e controles das operações e prestações deverão ser realizadas nos seguintes livros:

- Livro caixa, no qual deverá estar escriturada toda a sua movimentação financeira e tributária;

- Livro registro de inventário, no qual deverão contar registrados os estoques existentes no término de cada ano calendário, quando contribuinte do ICMS;

- Livro registro de entradas, modelo 1 ou 1-A, destinado à escrituração dos documentos fiscais relativos às entradas de mercadorias ou bens, ou aquisições de serviços de transporte e de comunicação, efetuadas a qualquer título pelo estabelecimento, quando contribuinte do ICMS;

- Livro de registro dos serviços prestados, destinado ao registro dos documentos fiscais sujeitos ao ISS, quando contribuinte do ISS.

- Livro de registro de serviços tomados, destinado ao registro dos serviços tomados sujeitos ao ISS;

- Livro de registro de entrada e saída de selo de controle, caso exigível pela legislação do IPI;

- Livro de registro de impressão de documentos fiscais, pelo estabelecimento gráfico para registro dos impressos que confeccionar para terceiros ou para uso próprio;

14 LEMBI, Claudenir; REIS, Luciano. A importância $e$ obrigatoriedade da escrituração contábil perante a legislação comercial, fiscal $e$ profissional. Disponível em: <http://www.crcpr.org.br/new/ content/publicacao/revista/revista134/escrituracao.htm. P. Acesso em: 20 dez. 2013. 
- Livros específicos pelos contribuintes que comercializem combustíveis;

Caso a empresa optante pelo Simples Nacional possua escrituração completa, com Livro Diário e Livro Razão, a escrituração do Livro Caixa é suprimida.

\section{Micro e pequenas empresas: tratamento diferenciado.}

As microempresas e empresas de pequeno porte optantes pelo Simples Nacional devem manter um sistema completo de escrituração contábil, podendo, opcionalmente, adotar modelo simplificado regulamentado pelo Comitê Gestor, conforme o art. $27^{15}$ da Lei Geral:

Art. 27. As microempresas e empresas de pequeno porte optantes pelo Simples Nacional poderão, opcionalmente, adotar contabilidade simplificada para os registros e controles das operações realizadas, conforme regulamentação do Comitê Gestor.

Conforme o artigo 27 do Estatuto Nacional da Micro e Pequena Empresa, o Comitê Gestor do Simples Nacional é órgão competente para regulamentar a escrituração contábil das Micro e Pequenas Empresas. A Resolução CGSN no 28/08 regulamentou o artigo 27 da Lei Geral e também conferiu poderes ao Conselho Federal de Contabilidade para editar resoluções disciplinando o significado de Contabilidade Simplificada, em conformidade com as disposições previstas no Código Civil Brasileiro. Vejase a transcrição que segue ${ }^{16}$ :

Art. $2^{\circ}$ Fica acrescido o art. 13-A na Resolução CGSN no 10, de 28 de junho de 2007, com a seguinte redação:

15 BRASIL. Ministério da Fazenda. Resolução CGSN ñ 10, de 28 de junho de 2007. Dispõe sobre as obrigações acessórias relativas às microempresas e empresas de pequeno porte optantes pelo Regime Especial Unificado de Arrecadação de Tributos e Contribuições (Simples Nacional). Disponível em: <http://www.receita.fazenda. gov.br/Legislacao/Resolucao/2007/CGSN/Resol10.htm>. Acesso em: 2 jun. 2014

16 BRASIL. Ministério da Fazenda. Resolução CGSN $N^{0} 28$, de 21 de janeiro de 2008. Altera a Resolução CGSN n 10, de 28 de junho de 2007, que dispõe sobre as obrigações acessórias relativas às microempresas e empresas de pequeno porte optantes pelo Regime Especial Unificado de Arrecadação de Tributos e Contribuições (Simples Nacional). Disponível em: <http://www.receita.fazenda. gov.br/Legislacao/Resolucao/2007/CGSN/Resol10.htm>. Acesso em: 2 jun. 2014. (grifo nosso)
Art. 13-A. As microempresas e empresas de pequeno porte optantes pelo Simples Nacional poderão, opcionalmente, adotar contabilidade simplificada para os registros e controles das operações realizadas, atendendo-se às disposições previstas no Código Civil e nas Normas Brasileiras de Contabilidade editadas pelo Conselho Federal de Contabilidade.

As normas, interpretações e comunicados técnicos elaborados pelo CFC devem ser aplicados às demonstrações contábeis para fins gerais e outros relatórios financeiros de todas as empresas com fins lucrativos. As demonstrações contábeis para fins gerais são dirigidas às necessidades comuns de vasta gama de usuários externos à entidade, por exemplo, sócios, acionistas, credores, empregados e o público em geral. O objetivo das demonstrações contábeis é oferecer informação sobre a posição financeira (balanço patrimonial), o desempenho (demonstração do resultado) e fluxos de caixa da entidade, que seja útil aos usuários para a tomada de decisões econômicas.

O Comitê de Pronunciamentos Contábeis emite Pronunciamentos, Interpretações e Orientações sempre em convergência com as IFRS emitidas pelo IASB, o Conselho Federal de Contabilidade homologa tais pronunciamentos do CPC por meio de Resolução aprovando a respectiva NBC TG - Norma Brasileira de Contabilidade - Técnica Geral. Cada CPC gera uma NBC TG com o mesmo número. ${ }^{17}$

\subsection{Escrituração contábil simplificada - NBC T 19.13.}

Dentro da competência conferida ao Conselho Federal de Contabilidade foi elaborada a NBC T 19.13 (Norma Brasileira de Contabilidade Técnica), a qual restou aprovada pela Resolução no 1.115/07.

A NBC T 19.13 aplicava-se às Microempresas e às Empresas de Pequeno Porte, optantes ou não pelo Simples Nacional, desde que fossem caracterizadas como tal no termos da Lei Geral (LC no 123/06). Ou seja, a Microempresa e a Empresa de Pequeno Porte que perdessem a condição de receber os benefícios concedidos pela referida LC $\mathrm{n}^{\circ} 123 / 06$ deveriam

17 DELOITTE Publicações. Demonstrações financeiras Exercicio de 2013. O aperfeiçoamento das regras contábeis brasileiras. Disponível em: $\quad<$ http://www.deloitte.com/assets/Dcom-Brazil/Local $\% 20$ Assets/Documents/Servi\%C3\%A7os/GuiaDF_\%202013.pdf>. Acesso em: 15 dez. 2013. 
proceder contabilmente como as demais empresas de regime normal, ou seja, Lucro Real ou Lucro Presumido.

A NBC T 19.13 determinava que a microempresa e a empresa de pequeno porte deveriam elaborar, ao final de cada exercício social, o Balanço Patrimonial e a Demonstração do Resultado. E era facultada a elaboração da Demonstração de Lucros ou Prejuízos Acumulados, da Demonstração das Mutações do Patrimônio Líquido, da Demonstração das Origens e Aplicações de Recursos e das Notas Explicativas ${ }^{18}$ e o Balanço Patrimonial e a Demonstração do Resultado deveriam ser transcritos no Livro Diário, assinados por profissional de contabilidade legalmente habilitado e pelo empresário.

As receitas, despesas e custos eram escriturados contabilmente com base na sua competência. Nos casos em que havia opção pelo pagamento de tributos e contribuições com base na receita recebida, a microempresa e empresa de pequeno porte devem efetuar ajustes a partir dos valores contabilizados, com vistas ao cálculo dos valores a serem recolhidos.

As microempresas e a empresas de pequeno porte elaboravam, ao final de cada exercício social, o Balanço Patrimonial e a Demonstração do Resultado, lhes sendo facultada a elaboração da Demonstração de Lucros ou Prejuízos Acumulados, da Demonstração das Mutações do Patrimônio Líquido, da Demonstração das Origens e Aplicações de Recursos e das Notas Explicativas. O Balanço Patrimonial e a Demonstração do Resultado eram transcritos no Livro Diário, assinados por profissional de contabilidade legalmente habilitado e pelo empresário.

O procedimento de escrituração contábil estipulado pela NBC TG 19.13 era simples e praticamente sem burocracia, todavia, com adoção dos padrões internacionais, a partir da Lei $11.638 / 2007^{19}$, houve a

18 Descrição resumida das operações da entidade e suas principais atividades.

19 A referida Lei alterou e revogou dispositivos da Lei no 6.404/1976 e estendeu às sociedades de grande porte disposições relativas à elaboração e divulgação de demonstrações financeiras. A Lei 11638/07 gerou mudanças na Lei das Sociedades por Ações (Lei 6404/76) que vigorava há 30 anos na contabilidade brasileira, para que a mesma se adeque aos padrões internacionais com maior transparência e qualidade das informações contábeis. Essas alterações envolvem vários tipos societários e a adoção das normas da Lei 11.638/07 deve ser feita não só pelas empresas de Sociedades Anônimas (S/A), mas também por todas as empresas obrigadas a seguir a Lei das S/A, o que inclui além das S/A, as empresas Limitadas (LTDA) tributadas pelo Lucro Real (Decreto 1.598/77) e também as empresas de grande porte. necessidade de modificação das exigências tendo em vistas as adequações internacionais.

\subsection{Padrões contábeis e convergência com os padrões internacionais: NBC TG 1000}

Na década de 60, a contabilidade passa a ter um papel preponderante no âmbito de expansão do mercado de capitais norte americano, passando então a ter a capacidade de fornecer informações que sejam úteis ao processo de decisório dos usuários. Em um contexto de mercados globalizados, emerge a preocupação acerca da construção contabilidade internacional, cuja finalidade precípua é incentivar os investimentos estrangeiros, a partir da unificação das normas contábeis, e facilitar a compreensão das informações divulgadas no mercado, o objetivo seria reduzir as dúvidas de natureza contábil, diminuindo as incertezas inerentes ao processo decisório de investimento. Os padrões internacionais da contabilidade possuem como fundamentos a maior a transparência, clareza e compreensão das informações financeiras das empresas. ${ }^{20}$

O International Accounting Standards Board (IASB) é uma entidade do setor privado, independente, com sede em Londres, Grã-Bretanha, constituída por mais de 140 entidades profissionais de todo o mundo, incluindo o Brasil representada pelo Instituto Brasileiro de Contadores - IBRACON e o Conselho Federal de Contabilidade - CFC. Relativamente a sua estrutura, o IASB é vinculado à Fundação para o Comitê de Normas Internacionais de Contabilidade, com sede em Delaware, Estados Unidos da América. Atualmente, edita as normas internacionais de contabilidade e lidera o processo de convergência dos padrões contábeis, é reconhecido por parte de profissionais da área, acadêmicos e usuários das informações contábeis.

O IASB institui as Normas Internacionais de Contabilidade, as International Financial Reporting Standards - IFRS, que pretendem ser aplicadas a todas as empresas. Essas normas foram recepcionadas no Brasil, combinando com a criação do CPC - Comitê de Procedimentos Contábeis. No Brasil, a Lei 11.638/07 (IFRS FULL) foi publicada com o objetivo de alinhar

20 ANTUNES, Jeronimo; ANTUNES, Guilherme; PENTEADO, Isis. A convergência contábil brasileira e a adoção das normas Internacionais de contabilidade: o ifrs-1. Disponível em: <http:// www.ead.fea.usp.br/Semead/10semead/sistema/resultado/ trabalhosPDF/30.pdf $\geq$. Acesso em: 23 dez. 2013. 
os Procedimentos da Contabilidade Brasileira ao padrão internacional de Normas Contábeis, e a partir do exercício iniciado em $1^{\circ}$ de janeiro de 2010, as pequenas e médias empresas passaram a ter a obrigação de elaborar suas demonstrações contábeis de acordo com as determinações da NBC TG 1000, aprovada pela Resolução CFC no 1.255/09 do Conselho Federal de Contabilidade. Todavia, a referida norma do CFC não fazia diferenciação entre médias empresas, pequenas e microempresas. ${ }^{21}$

Ointuito da Resoluçãoé a convergência com as Normas Internacionais de Contabilidade ${ }^{22}$ emitidas pelo IASB (Comitê de Normas Internacionais de Contabilidade), de uma forma mais simplificada. O CFC passou então a adotar o conceito estabelecido pelo IASB considerando pequenas e médias empresas como empresas que:

(a) não têm obrigação pública de prestação de $\operatorname{contas}^{23} ; \mathrm{e}$

(b) elaboram demonstrações contábeis para fins gerais para usuários externos. Exemplos de usuários externos incluem proprietários que não estão envolvidos na administração do negócio, credores existentes e potenciais, e agências de avaliação de crédito.

O Comitê de Normas Internacionais de Contabilidade considera empresas pequenas e médias as sociedades fechadas e sociedades que não sejam requeridas a fazer prestação pública de suas contas, assim como, aquelas que possuam ativo total até $\mathrm{R} \$ 240$ milhões ou com receita bruta anual igual ou inferior a R \$ 300 milhões. Tais conceitos são divergentes dos utilizados na legislação brasileira. ${ }^{24}$

21 MAIOR, Verônica Souto. ITG 1000: Modelo contábil simplificado para

microempresas e empresas de pequeno porte. Disponível em: <http://www.sescapce.org.br/web/i/arquivos/1357933784.pdf>. Acesso em: 19 dez. 2013.

22 As normas IFRS são adotadas por 81 países, incluindo os membros da União Europeia no tocante às normas referentes às pequenas e médias empresas (NBC TG 1000) dos 80 países, somente 30 adotaram as regras internacionais.

23 Uma empresa tem obrigação pública de prestação de contas se: (a) seus instrumentos de dívida ou patrimoniais são negociados em mercado de ações ou estiverem no processo de emissão de tais instrumentos para negociação em mercado aberto (em bolsa de valores nacional ou estrangeira ou em mercado de balcão, incluindo mercados locais ou regionais); ou (b) possuir ativos em condição fiduciária perante um grupo amplo de terceiros como um de seus principais negócios. Esse é o caso típico de bancos, cooperativas de crédito, companhias de seguro, corretoras de seguro, fundos mútuos e bancos de investimento.

24 MAIOR, Verônica Souto. ITG 1000: Modelo contábil simplificado para microempresas e empresas de pequeno porte. Disponível em: <http://
As 35 Seções da NBC 1000 trazem diversas novidades nas práticas contábeis adotadas no Brasil, que devem ser cumpridas por essas empresas. O conjunto completo de demonstrações contábeis da entidade deve incluir todas as seguintes demonstrações:

a) Balanço patrimonial ao final do período;

b) Demonstração do resultado do período de divulgação;

c) Demonstração do resultado abrangente do período de divulgação. ${ }^{25}$ A demonstração do resultado abrangente pode ser apresentada em quadro demonstrativo próprio ou dentro das mutações do patrimônio líquido. A demonstração do resultado abrangente, quando apresentada separadamente, começa com o resultado do período e se completa com os itens dos outros resultados abrangentes;

d) Demonstração das mutações do patrimônio líquido para o período de divulgação ${ }^{26}$;

e) Demonstração dos fluxos de caixa para o período de divulgação;

f) Notas explicativas, compreendendo o resumo das políticas contábeis significativas e outras informações explanatórias.

Assim, conforme a NBC TG 1000, as demonstrações contábeis devem representar apropriadamente a posição patrimonial e financeira (balanço patrimonial), o desempenho (demonstração do resultado e demonstração do resultado abrangente) e os fluxos de caixa da entidade. A apresentação adequada exige a representação confiável dos efeitos das transações, outros eventos e condições de acordo com as definições e critérios de reconhecimento para ativos, passivos, receitas e despesas.

O objetivo do Conselho Federal de Contabilidade é a adoção plena da NBC TG 1000. De acordo com

www.sescapce.org.br/web/i/arquivos/1357933784.pdf>. Acesso em: 19 dez. 2013.

25 Se a entidade não possui nenhum item de outro resultado abrangente em nenhum dos períodos para os quais as demonstrações contábeis são apresentadas, ela pode apresentar apenas a demonstração do resultado.

26 Se as únicas alterações no patrimônio líquido durante os períodos para os quais as demonstrações contábeis são apresentadas derivarem do resultado, de distribuição de lucro, de correção de erros de períodos anteriores e de mudanças de políticas contábeis, a entidade pode apresentar uma única demonstração dos lucros ou prejuízos acumulados no lugar da demonstração do resultado abrangente e da demonstração das mutações do patrimônio líquido (ver o item 6.4). 
a referida Norma, o CFC analisou o processo de implementação da NBC TG 1000 pelas pequenas e médias empresas no Brasil, desde a sua edição, em 2010, até o presente momento, e com base em vários aspectos, entre eles, merecem destaque: as iniciativas promovidas pelo IASB, que preveem ciclos de revisão das normas editadas e a flexibilização, por parte do CFC, da adoção da referida NBC para as entidades definidas como microempresas e empresas de pequeno porte, por meio da edição da ITG 1000, modelo contábil alternativo. ${ }^{27}$

Porém, com foco em adequar os padrões internacionais à realidade brasileira foi elaborado um padrão de procedimentos simplificados à luz da NBC T 1000, a ITG 1000.

\subsection{Novo paradigma para escrituração contábil para microempresas e empresas de pequeno porte - ITG 1000.}

A ITG 1000 se propõe a estabelecer critérios e procedimentos simplificados a serem observados pelas microempresas e empresas de pequeno porte, na medida em que as MPEs optarem pela adoção da ITG 1000 passam então a seguir suas normas e não mais as da NBC TG 1000. A NBC TG 1000 - Contabilidade para Pequenas e Médias Empresas passou a ter sua adoção obrigatória a partir dos exercícios iniciados em $1^{\circ}$ de janeiro de 2010 para todas as empresas definidas como "Pequenas e Médias Empresas", alcançando, inclusive, as microempresas e empresas de pequeno porte. ${ }^{28}$

ANBCTG1000,comojámencionadoanteriormente, possui 35 seções que definem o tratamento contábil para diversos tipos de eventos econômicos. Porém, várias seções estabelecem o tratamento contábil de transações e fenômenos que geralmente não ocorrem, ou não se fazem presentes, nas microempresas e empresas de pequeno porte brasileiras. ${ }^{29}$

27 NORMA BRASILEIRA DE CONTABILIDADE. CTG 1000: adoção plena da NBC TG 1000. Disponível em: <http:// portalcfc.org.br/wordpress/wp-content/uploads/2013/09/CTG1000.pdf>. Acesso em: 12 dez. 2013.

28 MAIOR, Verônica Souto. ITG 1000: Modelo contábil simplificado para

microempresas e empresas de pequeno porte. Disponível em: $<$ http://www.sescapce.org.br/web/i/arquivos/1357933784.pdf $>$. Acesso em: 19 dez. 2013.

29 FILHO, Benedito. ITG 1000: o impacto na contabilidade para ME e EPP. Disponível em: <http://www.convecon.com.br/ download/ITG1000.pdf>. Acesso em: 15 dez. 2013.
Assim, a ITG 1000 foi elaborada pelo CFC com o objetivo de propiciar um tratamento diferenciado para as microempresas e empresas de pequeno porte, visando à simplificação da escrituração e da geração de demonstrações contábeis, levando em consideração a realidade quanto ao porte, volume de negócios e de transações realizadas por esse conjunto de entidades. Ressalta-se, entretanto, que tal simplificação não enseja, sob quaisquer circunstâncias ou hipótese, o entendimento de que este grupo de empresas esteja desobrigado à manutenção de escrituração contábil. ${ }^{30}$

A sociedade empresária, a sociedade simples, a empresa individual de responsabilidade limitada ou o empresário a que se refere o Art. 966 da Lei no 10.406/02, que tenha auferido, no ano calendário anterior, receita bruta anual até os limites previstos nos incisos I e II do Art. $3^{\circ}$ da Lei Complementar no $123 / 06^{31}$ :

I - microempresa, receita bruta anual igual ou inferior a $\mathrm{R} \$ 360.000,00 \mathrm{e}$

II - empresa de pequeno porte receita bruta anual superior a $\mathrm{R} \$ 360.000,00$ e igual ou inferior a $\mathrm{R} \$$ $3.600 .000,00$.

A sua contabilidade deverá ser feita de acordo com a ITG $2000^{32}$, que se refere à escrituração contábil e é o padrão a ser seguido por todos os tipos de empresários. $\mathrm{E}$ as demonstrações contábeis/financeiras de acordo com a ITG 1000, que é o Modelo Contábil para Microempresa e Empresa de Pequeno Porte. ${ }^{33}$

A ITG 1000 alcança eventos e transações básicas, reestrutura o plano de contas e as demonstrações contábeis e cria novas obrigações para MPEs. Assim, demandará a reformulação de controles internos e planos de contas, o incremento de sistemas eletrônicos,

30

31 MAIOR, Verônica Souto. ITG 1000: Modelo contábil simplificado para microempresas e empresas de pequeno porte. Disponível em: <http://www.sescapce.org.br/web/i/arquivos/1357933784. pdf $>$. Acesso em: 19 dez. 2013.

32 A ITG 2000 é aplicável à todas empresas, independentemente de sua natureza ou de seu porte. Esta norma emitida pelo CFC estabelece critérios e procedimentos a serem adotados pela entidade para a escrituração contábil de seus fatos patrimoniais, por meio de qualquer processo, bem como a guarda e a manutenção da documentação e de arquivos contábeis e a responsabilidade do profissional da contabilidade.

33 FILHO, Benedito. ITG 1000: o impacto na contabilidade para ME e EPP. Disponível em: <http://www.convecon.com.br/ download/ITG1000.pdf $\geq$. Acesso em: 15 dez. 2013. 
o auxílio de consultorias externas e o treinamento especializado da mão de obra. ${ }^{34}$

As principais mudanças promovidas pela ITG 1000 são:

a) As receitas, as despesas e os custos do período da entidade devem ser escriturados contabilmente, de acordo com o regime de competência.

b) Os lançamentos contábeis no Livro Diário devem ser feitos diariamente, ou ao final de cada mês, desde que tenham como suporte os livros ou outros registros auxiliares escriturados em conformidade com a ITG 2000 - Escrituração Contábil, aprovada pela Resolução CFC no 1.330/11.

c) Para transações ou eventos materiais que não estejam cobertos por esta interpretação, a entidade deve utilizar como referência os requisitos apropriados estabelecidos na ITG 2000 - Escrituração Contábil e na NBC TG 1000 - Contabilidade para Pequenas e Médias. Ou seja, possui como normas subsidiárias a ITG-2000 e a NBC TG 1000. Eventos e transações não tratados pela ITG 1000 terão aplicação subsidiária das IFRS contidas na ITG-2000 - Escrituração Contábil e na NBC TG 1000 - Contabilidade para Pequenas e Médias Empresas. Tais normas possuem maior complexidade e reforçam a burocracia e os transtornos delas decorrentes.

d) O profissional da Contabilidade deve obter Carta de Responsabilidade da administração da entidade para a qual presta serviços cujo intuito é salvaguardar a sua responsabilidade pela realização da escrituração contábil do período-base encerrado, segregando-a e distinguindo-a das responsabilidades da administração da entidade.

e) A entidade deve elaborar o Balanço Patrimonial, a Demonstração do Resultado e as Notas Explicativas ao final de cada exercício social. Quando houver necessidade, a entidade deve elaborá-los em períodos intermediários. No âmbito da NBC T 19.13 não havia exigência de Balanço Patrimonial comparativo e exigência de evidenciação do movimento, a partir da ITG 1000 há necessidade do Balanço Patrimonial comparativo e com evidenciação do movimento o que exigirá adequação dos sistemas contábeis utilizados. No âmbito da NBC T 19.13 as Notas Explicativas eram opcionais.

f) O custo dos estoques deve ser calculado considerando os custos individuais dos itens, sempre que possível. Caso não seja possível, o custo dos estoques deve ser calculado por meio do uso do método "Primeiro que Entra, Primeiro que Sai" (PEPS) ou o método do custo médio ponderado. Há a necessidade do controle dos itens imobilizados, o que determina que haja o seu controle permanente impondo maior detalhamento do plano de contas. No mesmo sentido, exige-se permanente acompanhamento do preço de mercado e a sua comparação com o custo de aquisição dos itens para revenda, almoxarifado ou produção.

Para melhor visualização do que será alterado, destaca-se ainda o seguinte quadro apontando as principais alterações a partir da adoção ITG 1000 em relação à NBC T 19.13:

34 BRASIL. Conselho Federal de Contabilidade. Resolução CFC n. ${ }^{\circ}$ 1.418/12. Aprova a ITG 1000 - Modelo Contábil para Microempresa e Empresa de Pequeno Porte. Disponível em: < http://www.contabeis.com.br/forum/topicos/88692/resolucaocfc-no-141812-itg-1000/>. Acesso em: 06 jun. 2014. 
Tabela 1

\begin{tabular}{|c|c|c|}
\hline & EXIGENCIAS DA ITG 1000 & EXIGENCIAS DA NBC T 19.13 \\
\hline Administração & $\begin{array}{l}\text { Carta de Responsabilidade da Administra- } \\
\text { ção cujo intuito é salvaguardar o contador } \\
\text { e distinguir possíveis ônus em decorrência } \\
\text { de má administração. }\end{array}$ & Não havia previsão na norma. \\
\hline \multirow[t]{4}{*}{$\begin{array}{l}\text { Demonstrações } \\
\text { Contábeis }\end{array}$} & $\begin{array}{l}\text { Balanço Patrimonial comparativo e com } \\
\text { evidenciação do movimento }\end{array}$ & $\begin{array}{l}\text { Balanço Patrimonial NÃO comparativo e sem } \\
\text { exigência de evidenciação do movimento. }\end{array}$ \\
\hline & $\begin{array}{l}\text { Demonstração de Resultados comparativa } \\
\text { e com evidenciação do movimento }\end{array}$ & $\begin{array}{l}\text { Demonstração do Resultado NÃO comparati- } \\
\text { vo e sem exigência de evidenciação do movi- } \\
\text { mento. }\end{array}$ \\
\hline & $\begin{array}{l}\text { Demonstração de Fluxos de Caixa } \\
\text { (opcional) }\end{array}$ & $\begin{array}{l}\text { Não existia Demonstração de Fluxos de } \\
\text { Caixa - DFC. Era facultativo a apresentação } \\
\text { da Demonstração de Lucros ou Prejuízos } \\
\text { Acumulados - DLPA, Demonstração das } \\
\text { Mutações do Patrimônio Líquido - DMPL e } \\
\text { das Demonstrações das Origens e Aplicações } \\
\text { dos Recursos - DOAR. }\end{array}$ \\
\hline & $\begin{array}{l}\text { Notas Explicativas com declarações } \\
\text { sobre o uso da ITG } 1000 \text { e de normas } \\
\text { subsidiarias, com narrativas sobre políticas } \\
\text { contábeis, contingencias passivas e detalhes } \\
\text { sobre itens que não constam das demais } \\
\text { demonstrações. Divulgação da Conciliação } \\
\text { do Imobilizado, considerando adições, } \\
\text { baixas, depreciação e outros movimentos. }\end{array}$ & Notas Explicativas eram opcionais. \\
\hline Plano de Contas & Conforme o modelo da ITG 1000 & $\begin{array}{l}\text { O Plano de Contas era conforme modelo esta- } \\
\text { belecido pela NBC T } 19.13 \text {. Era mais simplifi- } \\
\text { cado, com quatro níveis de contas }\end{array}$ \\
\hline \multirow[t]{3}{*}{ Avaliação de Estoques } & $\begin{array}{l}\text { Registro pelo menor valor entre o custo e o } \\
\text { valor de venda líquido (valor justo). }\end{array}$ & Não havia previsão na norma. \\
\hline & $\begin{array}{l}\text { Produtos acabados serão registrados pelo } \\
\text { valor de venda, deduzido das despesas } \\
\text { necessárias à futura comercialização. }\end{array}$ & Não havia previsão na norma. \\
\hline & $\begin{array}{l}\text { Produtos em elaboração devem ser } \\
\text { registrados pelo valor de venda deduzido } \\
\text { do custo para término da produção e das } \\
\text { despesas para a futura comercialização. }\end{array}$ & Não havia previsão na norma. \\
\hline
\end{tabular}

A Carta de Responsabilidade tem por objetivo distinguir as responsabilidades dos profissionais da contabilidade da dos administradores das microempresas e empresas de pequeno porte. ${ }^{35}$ A ITG 1000 recomenda a realização

35 BRASIL. Conselho Federal de Contabilidade. Resolução CFC n. ${ }^{\circ} 1.418 / 12$. Aprova a ITG 1000 - Modelo Contábil para Microempresa e Empresa de Pequeno Porte. Disponível em: < http://www.contabeis.com.br/forum/topicos/88692/resolucao-cfc-no-141812-itg-1000/>. 
de lançamentos diários, porém, permite que as microempresas e as empresas de pequeno porte façam os seus lançamentos contábeis somente ao final de cada mês. Para tanto, precisam manter a escrituração regular dos Livros e registros auxiliares em conformidade com as normas e a legislação fiscal vigentes. ${ }^{36}$

A ITG 1000 ainda estabelece que as microempresas e empresas de pequeno porte devem elaborar e divulgar o Balanço Patrimonial, a Demonstração do Resultado e as Notas Explicativas. O item 27 da ITG 1000 determina a elaboração e a divulgação do conjunto completo de Demonstrações Contábeis, incluindo Balanço Patrimonial, Demonstração do Resultado, Demonstração das Mutações do Patrimônio Líquido, Demonstração dos Fluxos de Caixa, Demonstração dos Resultados Abrangentes, além das Notas Explicativas. ${ }^{37}$

\subsection{Sped contábil: escrituração digital.}

Conforme o disposto no art. 32, inciso III, da Lei n.8934 $/ 94^{38}$, o Registro perante as juntas comerciais compreende a autenticação dos instrumentos de escrituração das empresas mercantis registradas e dos agentes auxiliares do comércio, na forma de lei própria. Assim sendo, é de competência da junta comercial o registro da escrituração contábil dos empresários e sociedade empresárias no Brasil.

No entanto, atualmente, existe a Escrituração Contábil Digital (ECD), de competência da Receita Federal. A ECD, também denominado como SPED contábil, é parte integrante do projeto SPED e tem por objetivo a substituição da escrituração em papel pela escrituração transmitida via arquivo, ou seja, corresponde à obrigação de transmitir, em versão digital, os seguintes livros:

I - livro Diário e seus auxiliares, se houver;

Acesso em: 06 jun. 2014.

36 BRASIL. Conselho Federal de Contabilidade. Resolucão CFC n. ${ }^{\circ}$ 1.418/12. Aprova a ITG 1000 - Modelo Contábil para Microempresa e Empresa de Pequeno Porte. Disponível em: < http://www.contabeis.com.br/forum/topicos/88692/resolucaocfc-no-141812-itg-1000/>. Acesso em: 06 jun. 2014.

37 BRASIL. Conselho Federal de Contabilidade. Resolução CFC n. 1.418/12. Aprova a ITG 1000 - Modelo Contábil para Microempresa e Empresa de Pequeno Porte. Disponível em: < http://www.contabeis.com.br/forum/topicos/88692/resolucaocfc-no-141812-itg-1000/>. Acesso em: 06 jun. 2014.

38 Lei Ordinária 8.934/1994. Publicada no D.O. DE 21/11/1994.
II - livro Razão e seus auxiliares, se houver;

III - livro Balancetes Diários, Balanços e fichas de lançamento comprobatórias dos assentamentos neles transcritos.

Segundo a Instrução Normativa RFB no 787/07, estão obrigadas a adotar a ECD:

I - em relação aos fatos contábeis ocorridos a partir de $1^{\circ}$ de janeiro de 2008 , as sociedades empresárias sujeitas a acompanhamento econômico-tributário diferenciado, nos termos da Portaria RFB $n^{\circ}$ 11.211, de 7 de novembro de 2007, e sujeitas à tributação do Imposto de Renda com base no Lucro Real.

II - em relação aos fatos contábeis ocorridos a partir de $1^{\circ}$ de janeiro de 2009, as demais sociedades empresárias sujeitas à tributação do Imposto de Renda com base no Lucro Real.

A partir do ano-calendário 2009, estão obrigadas ao Sped Contábil todas as sociedades empresárias tributadas pelo lucro real. Para as outras sociedades empresárias a ECD é facultativa. Dessa forma, percebese que as MPEs ainda não estão sujeitas à Escrituração Contábil Digital. ${ }^{39} \mathrm{Na}$ ECD, o empresário, a partir do seu sistema de contabilidade, gera um arquivo digital, podendo ser definido como "Livro Diário Digital", "Escrituração Contábil Digital - ECD", ou "Escrituração Contábil em forma eletrônica".

Ao receber a ECD, o Sped extrai um resumo (requerimento, Termo de Abertura e Termo de Encerramento) e o disponibiliza para a Junta Comercial competente. O objetivo é que os termos lavrados pela Junta Comercial, inclusive o de Autenticação, sejam transmitidos automaticamente à empresa durante a consulta acerca do andamento dos trabalhos. ${ }^{40}$

Conforme já ressaltado, as MPEs ainda não estão sujeitas à este tipo de escrituração. No entanto, vislumbra-se uma alteração de todo procedimento de escrituração contábil no Brasil, o novo procedimento passa a ter como parâmetros os requisitos exigidos pelo autoridade competente para editar normas sobre contabilidade, o Conselho Federal de Contabilidade.

39 BRASIL. Receita Federal. Sistema Público de Escrituração Digital. O que é. Disponível em: <http://www1.receita.fazenda.gov. br/sistemas/sped-fiscal/o-que-e.htm $\geq$. Acesso em: 08 jan. 2014.

40 BRASIL. Receita Federal. Sistema Público de Escrituração Digital. O que é. Disponível em: <http://www1.receita.fazenda.gov. br/sistemas/sped-fiscal/o-que-e.htm $\geq$. Acesso em: 08 jan. 2014. 
Desse modo, nota-se que o padrão de escrituração contábil poderá ser cobrado pela Receita Federal, uma vez que existe uma integração entre Receita, CFC e Juntas Comerciais, havendo assim, a utilização dos padrões contábeis instituídos pelo CFC no âmbito do SPED contábil.

\section{Posições acerca da adoção da ITG 1000}

Primeiramente, cabe ressaltar que a adoção das normas, a princípio, gerará uma ampliação de custos, pois haverá aumento de valor dos honorários do Contador, em razão da necessidade de adaptar o sistema, plano de contas, histórico de operações a cada empresa para cada empresa. Atualmente, o serviço de Contabilidade, muitas vezes, é prestado sem qualquer personalização e também sem qualquer utilidade para o administrador. Ademais, a realidade do micro e pequeno empresário brasileiro não contempla a contratação de contador para elaboração dos livros obrigatórios, estes empresários utilizam-se de tabelas e planilhas eletrônicas, armazenadas em locais diferentes e dissociadas umas das outras. Ou seja, haverá necessariamente uma adaptação aos novos padrões impostos pelas regras da ITG 1000.

A ITG 1000 exige que o Contador formalize sua relação com a empresa por meio de um contrato de Prestação de Serviços e anexe ao contrato uma Carta de Responsabilidade da Administração, por meio da qual, o administrador declara que as informações fornecidas ao Contador são fidedignas; os controles internos adotados pela empresa são adequados; não realizou nenhum tipo de operação ilegal; todos os documentos fornecidos estão revestidos de total idoneidade; os estoques foram avaliados, contados e levantados fisicamente; não houve fraude envolvendo administração ou empregados; não houve violação de leis, normas ou regulamentos. Tal exigência demandará do contabilista grande capacidade de persuasão para convencer o administrador a assinar a referida carta.
O levantamento de todos os dados exigidos para escrituração contábil deverá ser feito pelo administrador ou pessoa nomeada por ele, em geral, um funcionário, para estabelecer o elo entre a empresa e o prestador do serviço contábil. Será necessário reformular os controles internos e planos de contas, incrementar os sistemas eletrônicos, com o auxílio de consultorias externas e o treinamento especializado da mão de obra.

Nota-se que, de fato, a ITG 1000 passou a ser uma opção mais complexa. A microempresa ou a empresa de pequeno porte que não adotar a ITG 1000 terá que se submeter aos dispositivos da NBC TG 1000 ou das Normas Brasileiras de Contabilidade Técnicas Gerais completas, as quais têm uma complexidade ainda maior e um número de obrigações ainda superiores.

A escrituração contábil tal qual é proposta pela ITG 1000, com obviedade modifica o sistema de escrituração, o que traz uma adequação necessária e, por consequência, gera a oneração do empresário. Por outro lado, potencializa a tentativa de inserção das MPEs em um ambiente internacionalizado. A justificativa para adoção dos padrões internacionais é a existência de potenciais credores e agências de avaliação de crédito, assim como desenvolver um conjunto único de normas contábeis globais, compreensíveis e exequíveis que exijam informações transparentes e comparáveis em demonstrações financeiras e outros relatórios financeiros, para ajudar os participantes nos mercados de capital do mundo e outros usuários a tomarem decisões econômicas. ${ }^{41}$

Grande parte dos Estados do mundo vem adotando os padrões internacionais, conforme pode ser visualizado pelo mapa a seguir:

\section{Quadro 1}

41 Dois terços dos países do G20 e quase metade das companhias da Global Fortune 500 divulgam suas demonstrações financeiras adotando as IFRSs. 


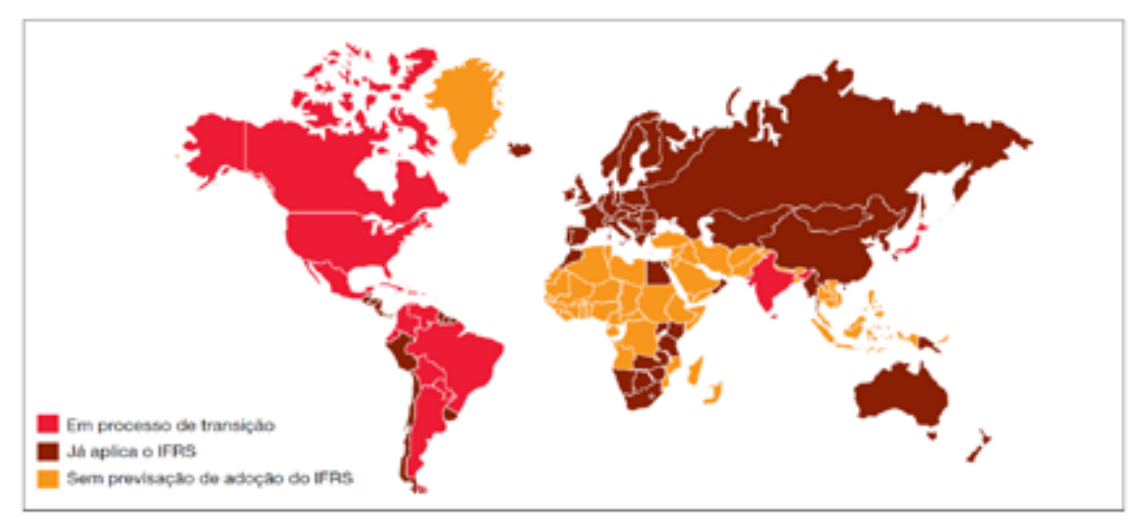

Fonte: IFRS e CPCs - A nova contabilidade brasileira, PWC.

No entanto, é necessário destacar alguns pontos controvertidos sobre a adoção desses parâmetros no âmbito nacional, por meio da ITG 1000.

Cumpre ressaltar que o principal papel da contabilidade é o de apoio gerencial e societário dos empresários, não se prestando à função de ser mero instrumento fiscal pelos órgãos de controle e fiscalização, e a exigência da escrituração contábil não pode ser utilizada como instrumento punitivo, prejudicando gravemente a vida dos pequenos empresários brasileiros.

Ademais, é possível questionar a competência do Conselho Federal de Contabilidade para exigir a adoção compulsória das Normas Internacionais por empresas e instituições brasileiras que sequer foram alcançadas pela Lei 11.638/2007, vez que a lei trata de sociedades de grande porte. Não existe nenhuma lei especial que determine expressamente que a autoridade fazendária possa examinar a aplicação das aludidas normas nominadas como internacionais de contabilidade, mesmo porque a escrituração contábil deve ser apresentada frente à Junta Comercial competente pelo registro empresarial, a Receita somente atua como um órgão intermediário a quem são remetidas as informações. Ademais, não existe lei que atribua a qualquer órgão o direito de realizar o referido exame com tal fim específico.

No tocante à atividade fiscalizatória dos Conselhos de Contabilidade, a alínea "c" do artigo 10 do Decretolei $\mathrm{n}^{\circ}$ 9.295/46 não autoriza a entrega de livros contábeis aos fiscais do CRC. Esse dispositivo refere-se à competência dos Conselhos Regionais para fiscalizar o exercício da profissão de contador visando a impedir e punir infrações relacionadas à profissão contábil. A empresa, inclusive, pode impedir a entrega dos livros contábeis aos fiscais do CRC, pois, os livros são propriedades privadas. E, excetuadas as hipóteses de fiscalização fazendária, como dispõe o artigo 1.193 do Código Civil, e de autorização judicial, essa propriedade privada não pode ser violada. Assim, diante deste questionamento, indaga-se quem será multado se os livros contábeis não estiverem escriturados segundo as Normas Internacionais de Contabilidade, a micro ou pequena empresa ou o contabilista?

Outro ponto a ser enfrentado, é o contabilista poder ser punido conforme os artigos 27 a 35 do Decreto-Lei 9.295/1946, entretanto, nenhum desses artigos prevê punição do contabilista em razão do descumprimento da Lei 11.638/2007 na contabilidade de micro e pequenas empresas, vez que a referida Lei não tem incidência perante as MPEs.

Haverá ainda uma ampliação considerável da capacidade de indução ao cumprimento das normas contábeis. Atualmente, a Receita Federal não dispõe de mecanismos automáticos que indiquem quais micro e pequenas empresas realizam contabilidade. É preciso que o fiscal se dirija a cada empresa. Com a ITG 1000 será possível incorporar a contabilidade ao SPED. Ainda que não haja uma data específica para tanto, com a exigência da contabilidade eletrônica, a Receita Federal poderá identificar com precisão e autuar automaticamente todas as empresas que não cumprem as exigências contábeis. Logo, a fiscalização orientadora é imprescindível para a indução ao cumprimento de forma menos traumática. 


\section{Conclusão}

A adoção da ITG 1000 pode ser questionada a partir sua operacionalização, sobretudo, no tocante à atividade de fiscalização do cumprimento da norma, tanto em relação aos Conselhos como à própria Receita Federal. No que se refere às determinações da ITG 1000, vislumbra-se a convergência com os padrões internacionais podendo ser benéfica à possibilidade de inserção das MPEs no mercado internacional, especialmente às Pequenas Empresas, que possuem uma maior articulação negocial.

Os procedimentos para cumprir as regras de escrituração contábil estão sendo alterados, a realidade de um sistema de escrituração digital confere efetividade às exigências de escrituração contábil. Por meio do ECD as informações solicitadas aos empresários, que por enquanto somente é exigido daqueles empresários tributados pelo lucro real, são pautadas pelas normas do Conselho Federal de Contabilidade.

A adequação dos padrões contábeis insere os microempresários e empresários de pequeno porte em um movimento de internacionalização de empresas. Todavia, neste contexto, a imputação de um ônus às MPEs não parece justa, sobretudo quando há possibilidade deste ônus ser acrescido de sanções desarrazoadas em decorrência da adaptação dos padrões de escrituração contábil.

De qualquer modo, como não se exige informações que já não sejam obrigatórias atualmente, apenas se altera o modo de informar os livros obrigatórios, não há impedimentos legais para a implementação da ITG 1000 e da sua posterior exigência via SPED.

Ressalta-se que a convergência aos padrões contábeis internacionais, por meio da adoção da ITG 1000, e a possibilidade da cobrança da adequação por parte das MPEs, trará o ônus de adequação da atual realidade dos empresários às novas exigências. As MPEs que não faziam a escrituração contábil conforme os referidos padrões terão a necessidade de contratar serviços de contabilistas, tanto para atualização como para manutenção de sua escrituração contábil.

As Normas Internacionais de Contabilidade, emitidas pelo Comitê Internacional de Contabilidade (IASB), constituem, hoje, uma fonte de referência para as práticas contábeis mundiais. Pelo fato de representarem um conjunto de normas constantemente atualizadas com as atuais exigências do mercado mundial, as Normas Internacionais (IFRS) têm sido aceitas, gradativamente, em diversos países, como suas próprias práticas contábeis ou com algumas adaptações. O que se verifica é que as normas contábeis brasileiras vêm sendo revisadas no sentido de obter uma convergência com os pronunciamentos emitidos pelo IASB.

\section{Referências}

ANTUNES, Jeronimo; ANTUNES, Guilherme; PENTEADO, Isis. A convergência contábil brasileira e a adoção das normas Internacionais de contabilidade: o ifrs-1. Disponível em: <http://www.ead.fea. usp.br/Semead/10semead/sistema/resultado/ trabalhosPDF/30.pdf.>.

BADIE, Bertrand, SMOUTS, Marie-Claude. La retournement du monde. Fundation National des Sciences Politique, 1995.

BRASIL. Conselho Federal de Contabilidade. Resolução CFC n. 1.418/12. Aprova a ITG 1000 - Modelo Contábil para Microempresa e Empresa de Pequeno Porte. Disponível em: < http://www.contabeis.com. br/forum/topicos/88692/resolucao-cfc-no-141812itg-1000/>. Acesso em: 06 jun. 2014.

BRASIL. Lei n. 10.406, de 10 de janeiro de 2002. Institui o Código Civil. Disponível em: <http://www.planalto. gov.br/ccivil_03/leis/2002/110406.htm>. Acesso em: 2 jun. 2014.

BRASIL. Lei n. 11.101, de 9 de fevereiro de 2005. Regula a recuperação judicial, a extrajudicial e a falência do empresário e da sociedade empresária. Disponível em: <http://www.planalto.gov.br/ccivil_03/_ato20042006/2005/lei/111101.htm>. Acesso em: 2 jun. 2014

BRASIL. Lei n. 6.404, de 15 de dezembro de 1976. Dispõe sobre as Sociedades por Ações. Disponível em: <http:// www.planalto.gov.br/ccivil_03/leis/16404consol. htm>. Acesso em: 2 jun. 2014.

BRASIL. Ministério da Fazenda. Resolução CGSN $n^{\circ}$ 10, de 28 de junho de 2007. Dispõe sobre as obrigações acessórias relativas às microempresas e empresas de pequeno porte optantes pelo Regime Especial Unificado de Arrecadação de Tributos e Contribuições (Simples Nacional). Disponível em: <http://www. receita.fazenda.gov.br/Legislacao/Resolucao/2007/ CGSN/Resol10.htm>. Acesso em: 2 jun. 2014. 
BRASIL. Receita Federal. Sistema Público de Escrituração Digital. O que é. Disponível em: <http:// www1.receita.fazenda.gov.br/sistemas/sped-fiscal/oque-e.htm $\geq$. Acesso em: 08 jan. 2014.

COMBACAU, Jean. Le droit international: bricàbrac ou système. In: BURGORGUE-LARSEN, Laurence. A internacionalização do diálogo dos juižes. Disponível em: <http://xa.yimg.com/kq/ groups/19791041/384304764/name/Laurence[1].pdf>.

DELOITTE Publicações. Demonstrações financeiras Exercicio de 2013: o aperfeiçoamento das regras contábeis brasileiras. Disponível em: <http://www.deloitte.com/ assets/Dcom-Brazil/Local\%20Assets/Documents/ Servi\%C3\%A7os/GuiaDF_\%202013.pdf>.

DELMAS-MARTY, Mirelle. Le force imaginantes du droit: le pluralisme ordonné. Editions du Seuil, 2006.

DUPUY, Pierre-Marie. L'unité de La ordre juridique international: cours general de droit international public. Leiden/Boston: Académie de Droit International de la Haye, 2003.

LEMBI, Claudenir; REIS, Luciano. A importância e obrigatoriedade da escrituração contábil perante a legislação comercial, fiscal e profissional. Disponível em: $<$ http:// www.crcpr.org.br/new/content/publicacao/revista/ revista134/escrituracao.htm>.

MAIOR, Verônica Souto. ITG 1000: Modelo contábil simplificado para

microempresas e empresas de pequeno porte. Disponível em: $\quad<$ http://www.sescapce.org.br/web/i/ arquivos/1357933784.pdf>.

ROULAND, N. Anthropologie juridique. PUF, 1998.

SACCO, Rodolfo. Lidée de droit commun par circulation de modèle et par stratification. In: RUIZFABRI, Helene; DELMAS-MARTY, Mirelle. Variations autour d'um droit commun.

TEUBNER, Gunther. Global Bukowina: Legal Pluralism in the World Society. In: TEUBNER, Gunther; FILHO, Benedito. ITG 1000: o impacto na contabilidade para ME e EPP. Disponível em: < http:// www.convecon.com.br/download/ITG1000.pdf.>.

TEUBNER, Gunther. Regime-Collisions: The vain search for legal unity in the fragmentation of global law. Michingan Journal of International Law, v. 25, n. 999, Summer 2004. 
Para publicar na Revista de Direito Internacional, acesse o endereço eletrônico www.rdi.uniceub.br ou www.brazilianjournal.org.

Observe as normas de publicação, para facilitar e agilizar o trabalho de edição. 